\title{
The use of a cusp-bearing homograft patch to the outflow tract and pulmonary artery in Fallot's tetralogy and pulmonary valvular stenosis
}

\author{
PAUL MARCHAND \\ From the Cardiovascular Research Unit, University of the Witwatersrand, and Department of Thoracic \\ Surgery, Johannesburg General Hospital
}

\begin{abstract}
A technique is described for maintaining pulmonary valve competence whilst widening the hypoplastic pulmonary artery ring found invariably in Fallot's tetralogy and pulmonary valve stenosis. A homograft composed of the aortic cusps, a portion of ascending aorta, and the anterior mitral leaflet is used. One, two, or three cusps may be replaced or added by variations of technique. The right ventricular outflow tract and the pulmonary trunk are also widened. The operation is applicable to children, and adult homografts can be used. The ring should be widened to a circumference of from 6 to $8 \mathrm{~cm}$. so as to prevent residual pressure gradients. One or two cusp replacements are favoured in the hope that growth will proceed because a continuous portion of natural pulmonary artery and ring remains untouched. An advantage of the technique is the small ventriculotomy required to excise the infundibular obstruction and close the ventricular septal defect. Four case histories are presented. Three patients have survived operation and are doing well. Up to six months post-operatively no serious pulmonary incompetence has developed.
\end{abstract}

Experience with total surgical correction for Fallot's tetralogy soon showed that the commonest cause of failure was incomplete relief of the pulmonary obstruction (Lillehei, Cohen, Warden, and Varco, 1956 ; Kirklin, Donald, Harshbarger, Hetzel, Patrick, Swan, and Wood, 1956). In an attempt to improve the results of operation, Lillehei and his co-workers (1956) introduced outflow tract patching in addition to wide resection of the infundibular muscle. This group has also emphasized that, in some cases, it is necessary to divide the ring and occasionally to extend the patch up to the bifurcation of the pulmonary artery (Lillehei et al., 1956; and Lillehei, Morris, Adams, and Anderson, 1964). Barnard and Schrire (1961) found it necessary to cross the valve ring in about half of their cases, but most surgeons are more conservative because they fear that pulmonary incompetence may be as great a burden for the right ventricle as residual stenosis. Lillehei et al. (1964) have suggested that a prosthetic pulmonary valve would be desirable in some cases and they mention experimental and limited clinical experience with this technique. Our group has described the use of a homograft pulmonary valve in a patient with massive pulmonary incompetence following pulmonary valvotomy (Fuller, Marchand, Zion, and Zwi, 1966). At catheterization a year later the valve was found to function satisfactorily. We were thereby encouraged to use valve homografts in four further cases, three of Fallot's tetralogy and one of so-called trilogy of Fallot. Unlike the published case, these all had small pulmonary rings and it was not possible to introduce a homograft valve without at the same time enlarging both the ventricular outflow and the pulmonary artery. It was proposed to use an aortic valve homograft with a short attached segment of ascending aorta to enlarge the pulmonary trunk and to widen the outflow tract with a Tefion patch. Shortly before surgery my colleague, Mr. L. du Plessis, suggested that the anterior leaflet of the mitral valve be left on the homograft for use as an outflow patch. The first case, though finally fatal, encouraged us to persevere, and the next three patients have done so well that it is felt that the technique should be reported.

\section{PREPARATION OF THE HOMOGRAFT}

The base of the heart is removed in the postmortem room and placed in a dilute solution of 
aqueous chlorhexidine (Hibitane). It is immediately dissected under clean but not sterile conditions. If early dissection is not possible the specimen is rapidly frozen to $-72^{\circ} \mathrm{C}$. and stored until dissection is convenient.

The ascending aorta is freed and both coronary arteries are dissected and ligated flush with the aortic wall. The left atrium is opened and the anterior and posterior mitral leaflets are separated by dividing the junctional tissue. The annulus is crossed and the incisions are carried through the left and right trigones aiming to include both noncoronary and left coronary cusps (Fig. 1). The right coronary cusp is freed from the interventricular septum by cutting the muscle beneath the base of that cusp along a line level with the mitral annulus (E-D in Fig. 1). This line corresponds with the basal ring described by Barratt-Boyes in his preparation of aortic valve grafts (1964). The mitral annulus lies at the base of the left coronary cusp and half the noncoronary cusp (du Plessis and Marchand, 1964), but, by retaining some of the firm fibrous trigone, it is possible to conserve continuity between the mitral leaflet and two complete cusps. After the chordae tendineae have been cut from the anterior mitral leaflet the aortic root, ascending aorta, and the anterior leaflet of the mitral valve can be removed en bloc.

A Tubb's dilator is introduced into the aortic ring and the blades are expanded until resistance is encountered. This measures half the circumference of the ring and is recorded as an index of the size of the graft. The circumference of the adult aortic ring has been found to vary between 6.5 and $9 \mathrm{~cm}$. (Table I). This agrees with BarrattBoyes' (1965) finding of an internal diameter range from 20 to $30 \mathrm{~mm}$. (circumference 6.3 to $9.5 \mathrm{~cm}$.). Loose tissue is removed from the adventitia, and the septal muscle beneath the right coronary cusp is trimmed to the minimum consistent with maintenance of a straight subvalvular border. The homograft is sterilized with ethylene oxide, freezedried, and stored (Marchand, 1958).

When, at operation, it is decided to widen the pulmonary ring the homograft is re-hydrated in an antibiotic solution (Marchand, 1958). If three cusps are to be retained the aortic wall is excised from the right coronary sinus leaving a $1-\mathrm{mm}$. fringe (Figs 1 and 2). At the apices of the com-

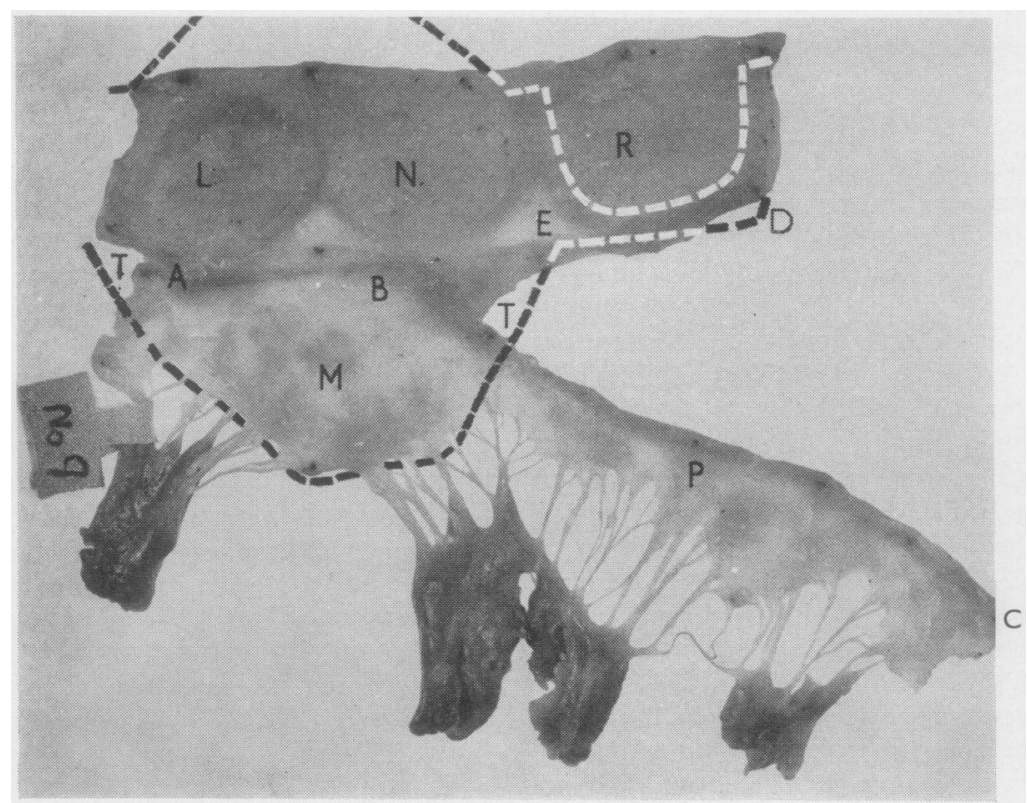

FIG. 1. 'Opened' specimen of mitral and aortic valves. The interrupted line marks the incisions described in the text for a three-cusp homograft. Noncoronary cusp $(N)$; right coronary cusp $(R)$; left cusp $(L)$. In actual preparation of the homograft the left and right cusps are not separated. $M$, anterior mitral leaflet; $P$, posterior mitral leaflet; $T$, trigones; $A, B, C$, mitral annulus; $A, B$, $D$, base of homograft; $E, D$, base of muscular interventricular septum. 
T A B L E I

MEASUREMENTS OF INTERNAL CIRCUMFERENCES OF THE AORTIC AND PULMONARY ARTERY RINGS OF SEVEN FRESH HEARTS USED FOR VALVE HOMOGRAFTS

\begin{tabular}{c|c|c|c}
$\begin{array}{c}\text { Age of Subject } \\
\text { (years) }\end{array}$ & $\begin{array}{c}\text { Aorta } \\
(\mathrm{cm} .)\end{array}$ & $\begin{array}{c}\text { Pulmonary } \\
\text { Artery (cm.) }\end{array}$ & Ratio $\frac{\text { Aorta }}{\text { P.A. \% }}$ \\
\hline 7 & 5.5 & $7 \cdot 5$ & 73 \\
8 & 5.5 & 7.1 & 77 \\
\hline 15 & 7.2 & 9.3 & 77 \\
\hline Average (child) & & & 76 \\
\hline 17 & 6.9 & $8 \cdot 5$ & 81 \\
24 & $7 \cdot 1$ & 8.5 & 83 \\
28 & 6.9 & $8 \cdot 1$ & 85 \\
35 & 8.1 & 9.5 & 85 \\
\hline
\end{tabular}

Average (adult)

82

The aortic ring circumference of 45 other adult grafts collected for aortic valve replacement has varied from 6.5 to $9 \mathrm{~cm}$.
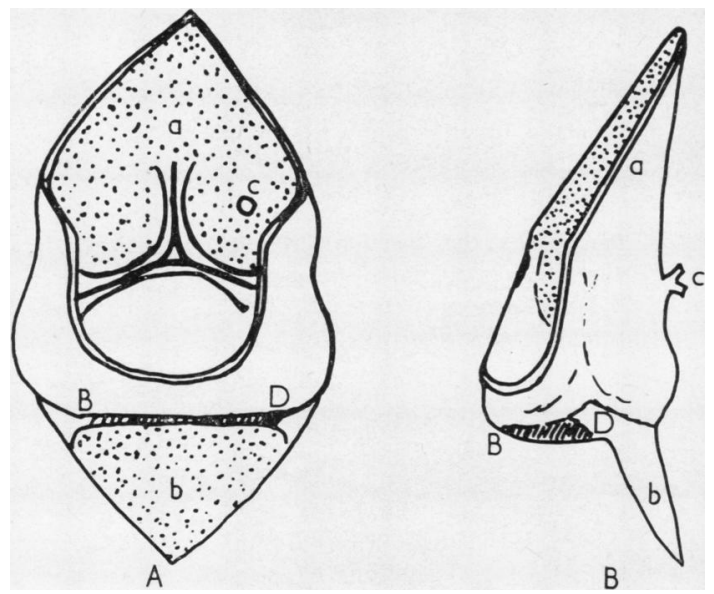

FIG. 2. Diagrams of the homograft. The stippled areas are the parts of the aorta and mitral leaflet used to enlarge the pulmonary artery and right ventricular outflow respectively. The cross-hatched line $(B-D)$ represents the muscular remnant of the ventricular septum. $(A)$ Viewed from behind with aortic wall excised from non-coronary cusp. $(B)$ Viewed from the side: $a$, tongue of aorta; $b$, mitral leaflet $c$, left coronary artery.

missural pillars of that cusp, two incisions are made to veer away from each other and obliquely transect the aorta. They meet about $1.5 \mathrm{~cm}$. above the commissural pillars in line with the commissure between the left and non-coronary cusps (Fig. 2). The specimen now consists of two roughly triangular tongues, the anterior leaflet of the mitral valve, and a portion of the aortic wall together with the intact aortic ring and the valve cusps (Fig. 2). Should two cusps be required for transplantation the right coronary is excised (Fig. 3). For a single-cusp patch the non-coronary cusp is retained and parts of the aorta and anterior mitral leaflet have to be cut away (Fig. 4).

\section{OPERATIVE TECHNIQUE}

The heart is exposed through a vertical sternotomy. It is prepared for cardiopulmonary bypass with reduction of body temperature to $30^{\circ} \mathrm{C}$. No attempt is made to separate the pulmonary artery from the aorta. On bypass, the pulmonary artery is incised longitudinally from its bifurcation to the valve ring. The cusps are inspected and any commissural adhesions are divided. The circumference of the ring is measured by expanding the blades of a Tubb's dilator until resistance is encountered. If the valve is bicuspid the ring is divided through the anterior commissure so as to preserve both cusps. If tricuspid, the incision is carried through the anterior cusp, which is thereby destroyed. The incision is continued through the right ventricular outflow far enough to permit excision of the obstructing muscle bands and exposure of the ventricular septal defect. The infundibular obstruction and septal defect can be dealt with through a limited ventriculotomy because of the additional access provided by the arteriotomy and ring division. Once the septal defect is closed, attention is directed towards the valve.

SINGLE-CUSP TRANSPLANT If the valve is bicuspid and the leaflets well formed they are both preserved and a single cusp is introduced. The first step is to fix accurately the lateral angles of the patch, which correspond with the base of the cusp (A-B in Fig. 4), to the divided host's arterial ring. This will line up the base of the new cusp with that of the natural ones. The homograft cusp will probably always be deeper and larger than those of the host, so that the height of the commissural pillars will not match. Once the bases of the cusps are correctly aligned the homograft is treated simply as an anterior patch. A continuous $4 / 0$ silk suture joins the aortic portion to the edge of the incised pulmonary artery, and this suture line approximates the commissures of host and donor as closely as possible. The apex of the anastomosis extends as far as necessary to widen the pulmonary artery, but I have always taken it up to the bifurcation. The anterior leaflet of the mitral valve is the proximal patch. This is tough and fibrous and is readily sewn with $3 / 0$ silk to the edges of the myocardium.

THREE-CUSP TRANSPLANT If all three cusps are to be replaced the natural cusps are excised. The 


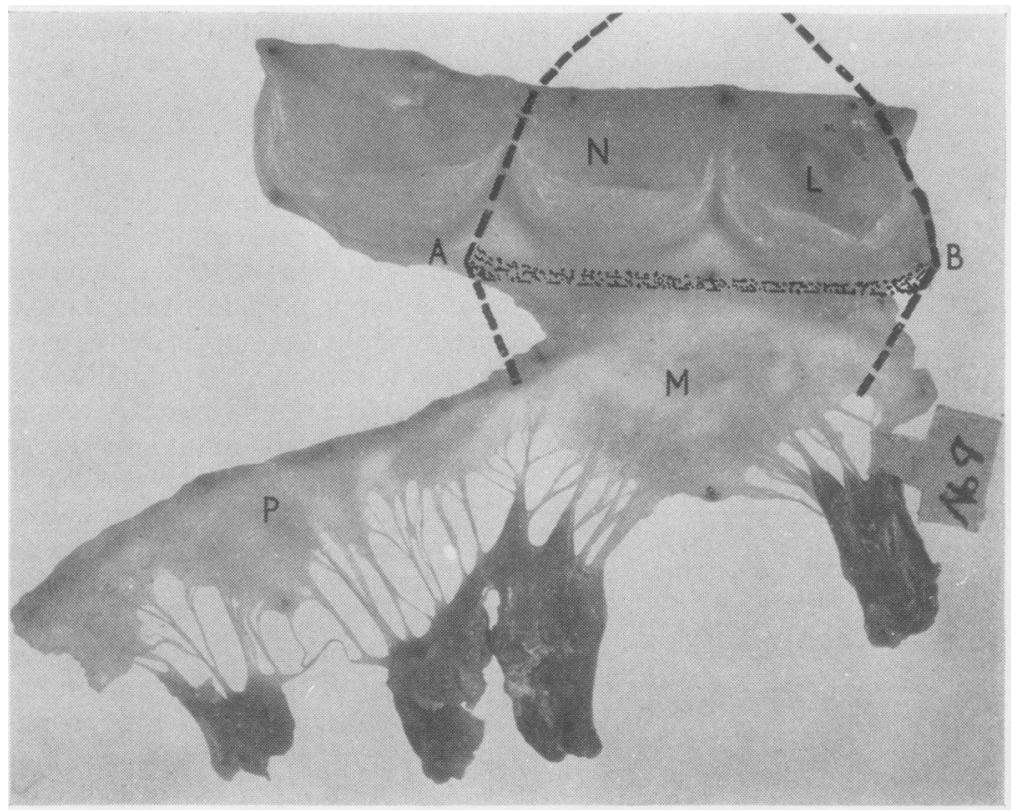

FIG. 3. The two-cusp patch. The interrupted line marks the incisions which demarcate the patch. The line $(A-B)$ beneath the cusps represents the aortic ring and is the widest portion of the patch. $N$, non-coronary cusp; $L$, left coronary cusp; $M$, anterior mitral leaflet; $P$, posterior mitral leaflet.

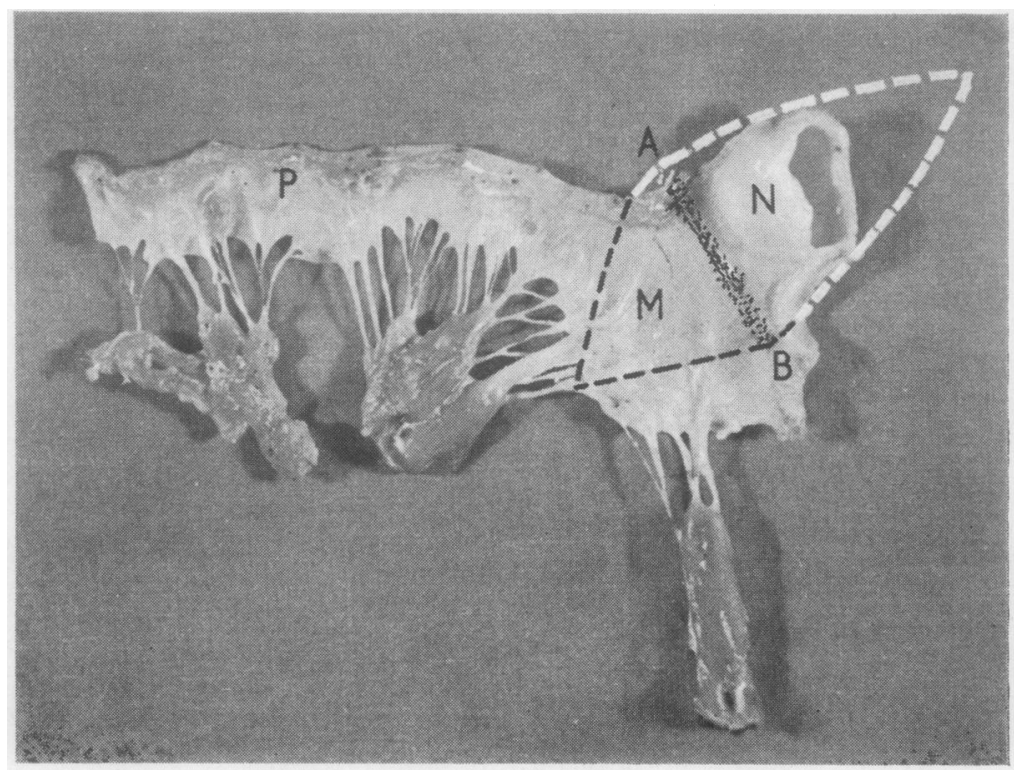

FIG. 4. Single-cusp patch. Only the non-coronary cusp is retained. Dotted line represents the outline of the patch. $A-B$ is the basal ring and this is the widest portion of the patch. $M$, anterior mitral leaflet; $P$, posterior mitral leaflet; $N$, non-coronary aortic cusp. 
intact ring of the host graft is placed within the gutter formed by the opened-out pulmonary trunk and, posteriorly, the aortic fringe of the right coronary cusp is sewn to the endothelium of the host artery. It must lie in an undistorted manner with its base accurately aligned with the host ring. Stitches then join the edges of the obliquely cut aortic margins to the endothelium of the pulmonary artery until the cut edges of the latter are reached. Thereafter suturing edge to edge between aortic graft and pulmonary artery is carried out distally. The basal ring of the homograft is sewn to the endothelium of the pulmonary artery ring until the cut edge of the pulmonary artery is reached, and thereafter the anterior mitral leaflet is sewn proximally to the myocardium to widen the outflow tract.

TWO-CUSP TRANSPLANT If one host cusp is to be retained and two homograft cusps transplanted the suturing is similar to that for total replacement. After two cusps have been excised the remaining one occupies only a third of the circumference of the pulmonary artery and the homograft has to be folded into the guttered pulmonary artery to fill the gaps created. The commissures will extend to a more distal level than those of the natural cusp, but the sutures pick up the apices of the natural commissures in an attempt to ensure cusp apposition during closure. The external surface of the homograft ring is sewn to the endothelium of the host ring up to its cut edges. Portions of the aortic and leaflet triangles will remain folded within the guttered pulmonary artery and ventricular cavity and these are sewn to the endothelium of the latter structures until their cut edges are reached. Thereafter edge to edge suturing completes the widening of the pulmonary artery and outflow tract of the right ventricle.

In all cases the anastomosis has been simple and the homograft has joined well to the thin pulmonary artery. Haemostasis has been no problem, but, as an insurance, the mitral patch has been reinforced with a covering of Teflon felt.

The aim is to enlarge the ring circumference without causing pulmonary incompetence. Depending upon the size of the patient, a ring circumference between 6 and $8 \mathrm{~cm}$. should be obtained. If the stretched width of the host ring is $1.5 \mathrm{~cm}$., then the host will contribute $3 \mathrm{~cm}$. towards the final circumference. One adult aortic cusp will provide about $2.5 \mathrm{~cm}$., so that with a bicuspid host valve where both cusps are retained, one additional adult cusp should provide a circumference of $5.5 \mathrm{~cm}$. With a tricuspid valve the host's contribution to the circumference of the ring will be reduced by the size of the cusps removed and more will be gained if two, rather than one, are replaced by the larger adult leaflets.

\section{CASE REPORTS}

CASE 1 S. S., a girl aged 5 with Fallot's tetralogy, weighed $30 \mathrm{lb}$. $(13 \mathrm{~kg}$.).

This little girl had been blue since birth. From the time she began to walk at $2 \frac{1}{2}$ years she had been breathless and had squatted. Cyanotic attacks became frequent after the age of 4 , and when admitted to hospital she was severely incapacitated and was unable to walk more than a few steps.

She was a thin, emaciated, intensely cyanosed child. She was investigated and catheterized by Dr. C. Rainier-Pope, who confirmed the diagnosis of Fallot's tetralogy and commented on the shortness of the ejection systolic murmur.

On 6 August 1966 operation was performed. A patent foramen ovale was confirmed but not closed. The pulmonary trunk was of reasonable size and the aorta was large. Three pulmonary cusps were present and these were formed but minute in size. The circumference of the valve ring was $2 \cdot 2 \mathrm{~cm}$. The incision was carried across the ring and for $1 \mathrm{~cm}$. through the anterior wall of the right ventricle. The infundibular obstruction was excised and the ventricular septal defect was closed with a Teflon patch. The valve cusps were excised and replaced with a homograft obtained from an 8-year-old child. The diameter of the new pulmonary ring was $5.6 \mathrm{~cm}$. The homograft anterior mitral leaflet was used to enlarge the outflow tract, and the triangular tongue of aorta widened the pulmonary trunk up to its bifurcation. Total by-pass time was 72 minutes. The heart maintained the burden of the circulation well and haemostasis was no problem. Needle pressures were recorded (Fig. 5). A gradient of $5 \mathrm{~mm}$. of mercury was present between the body of the right ventricle and the main pulmonary artery. The upper half of the pericardium was closed with catgut.

The child remained pink and well for the first 10 days, though a long, loud ejection systolic murmur was present. Radiographically, the lungs appeared to be well vascularized. From the tenth day onwards the jugular venous pressure began to rise and the liver to enlarge and eventually pulsate. Cyanosis reappeared on the fourteenth day. By the sixteenth day the child was severely dyspnoeic and $300 \mathrm{ml}$. of transudate was aspirated from the left pleura. Despite intensive therapy the congestive failure persisted and daily paracenteses of the left pleura were required. She died on the twenty-third day.

At necropsy no myocardial or pulmonary infarcts were present and the pulmonary arteries and veins were free of clot. The homograft cusps were healthy and mobile and histologically virtually normal. The ventricular septal defect was securely closed. The 


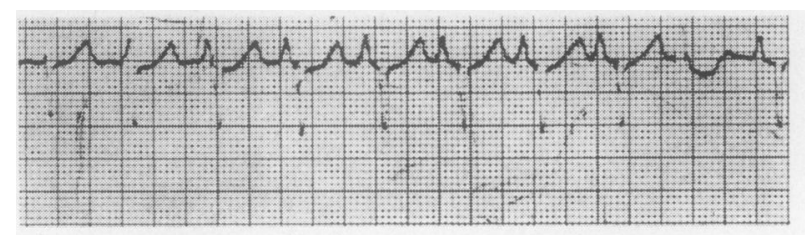

FIG. 5. Case 1. Withdrawal catheter pressure record taken at completion of the operation but before chest closure. Total valve replacement.

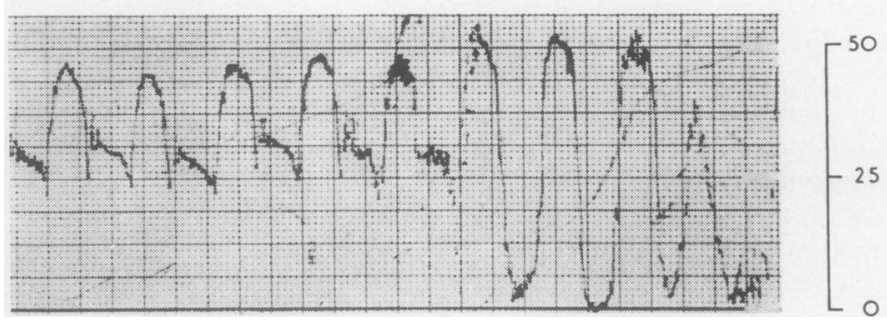

foramen ovale admitted a $0.5 \mathrm{~cm}$. probe. The upper portion of the pericardium had been closed and this had formed a fairly tight crescentic edge along the base of the grafted pulmonary artery. The suture lines of the homograft were well healed and free of thrombi. A stitch at the apex of the homograft patch had caught a crescentic flap at the origin of the left pulmonary artery, though the vessel was patent. In life this flap could have acted as a valve obstructing the entry of blood into the left lung. It is possible that the right heart failure was secondary to compression of the enlarged pulmonary trunk by the edge of the partly sutured pericardium, perhaps aggravated by a valvular obstruction to the origin of the left pulmonary artery.

CASE 2 L. B., a boy aged 18, had been cyanosed from infancy and a diagnosis of Fallot's tetralogy had been made in 1952. In that year Mr. L. Fatti performed a pulmonary valvotomy by dividing the valve with a Brock's valvotome. Considerable improvement followed and he remained well for 10 years. Latterly. dyspnoea and cyanosis of moderate degree had recurred. He was catheterized by Drs. J. Barlow and R. Tucker, who found a tight pulmonary valve stenosis producing an $80 \mathrm{~mm}$. of mercury gradient. Although the right ventricular infundibulum was hypertrophied, a gradient of only $10 \mathrm{~mm}$. of mercury existed at this level. No ventricular septal defect was found but an atrial septal defect was present.

Operation was performed on 20 August 1966. Dense adhesions were divided with some difficulty. A high foramen secundum. $2 \mathrm{~cm}$. in diameter, was closed with a Teflon patch. The pulmonary cusps were thick and rolled and had obviously been destroyed by the previous valvotomy. They were excised. The circumference of the valve ring was 3.8 $\mathrm{cm}$. The ring was divided anteriorly and the incision carried for $2 \mathrm{~cm}$. through the anterior wall of the diffusely hypertrophied right ventricle. An adult homograft with ring circumference of $7 \cdot 2 \mathrm{~cm}$. was sewn into the guttered base of the pulmonary artery, $\vec{\varphi}$ and the pulmonary trunk and right ventricular outflow tract were widened with the anterior mitral $\square$ leaflet and the ascending aortic wall. Bypass time was 90 minutes. Haemostasis was excellent. Needle pressures revealed a gradient of $10 \mathrm{~mm}$. of mercury between the body of the right ventricle and the pulmonary artery (Fig. 6). In view of our previous $\frac{\mathbb{\Phi}}{\varrho}$ experience the pericardium was left widely open.

Convalescence was uneventful apart from minor윽 wound sepsis, and he was discharged after five weeks. When last seen six months after surgery a short. faint ejection systolic murmur and a very faint early diastolic murmur were heard (Fig. 7). The pulmonary component of the second heart sound was loud.

CASE 3 C. G.. a boy aged 4, weighed $26 \mathrm{lb}$. (11 kg.). He had been cyanosed since birth. When 2 years old frequent syncopal attacks had occurred and a clinicalo diagnosis of Fallot's tetralogy was made. As a matter of urgency a shunt procedure was advised. On $30 \%$ December 1964 the heart was exposed through a left thoracotomy. The pericardium was opened and a dome-shaped pulmonary valvular stenosis was felt. . It was decided to dilate the pulmonary valve retro- $N$ gradely through the left pulmonary artery. The child improved post-operatively and cyanosis cleared. $\mathrm{He} O$ remained free of cyanotic attacks for a year and a N half, but thereafter symptoms recurred and rapidly progressed. He was investigated by Dr. J. Barlow in September 1966, and catheterization confirmed the diagnosis of Fallot's tetralogy with combined infund-\$ ibular and valvular stenosis.

On 24 September 1966 the heart was exposed through a vertical sternotomy. Adhesions from the previous operation were dense. A bicuspid valve was尺 present without commissural adhesions. The ring circumference was $4.2 \mathrm{~cm}$. The ring was transected precisely through the anterior commissure. retaining 


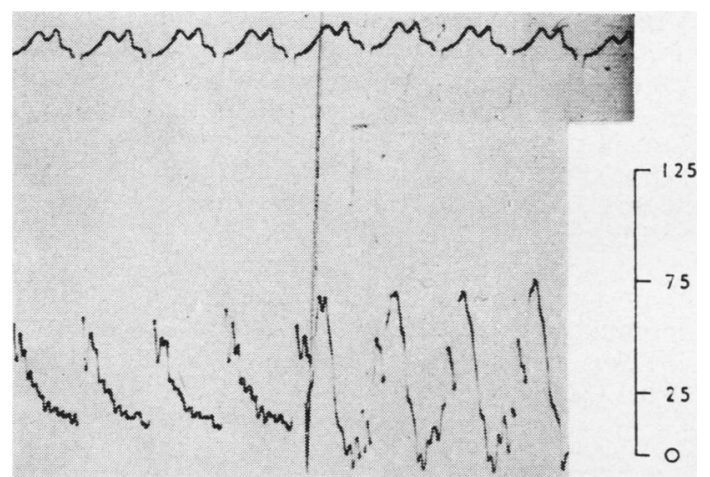

FIG. 6. Case 2. Needle pressures recorded between the body of the right ventricle and the pulmonary trunk at completion of surgery for total valve replacement.

two effective cusps. The right ventricle was cut for $1.5 \mathrm{~cm}$. to just short of a large coronary artery crossing the outflow tract. The fibrous stricture and considerable infundibular muscle were excised. The ventricular septal defect was closed with a patch. The right and left coronary cusps were then removed from an adult homograft with a ring circumference of $7.5 \mathrm{~cm}$. and the non-coronary cusp was interposed between the two natural cusps. The outflow tract was enlarged with the anterior mitral leaflet, and the pulmonary artery, as far as its bifurcation, was patched with aorta. The circumference of the reconstituted ring was $6 \cdot 2 \mathrm{~cm}$. Withdrawal pressures were recorded and a gradient of $15 \mathrm{~mm}$. of mercury was present between the body of the right ventricle and the pulmonary artery (Fig. 8). The pericardium was not closed. Bypass time was 95 minutes.

No post-operative cardiological difficulties were encountered, but the child was blind when he woke from the anaesthetic. Within 10 days he was ambulant and could walk around the ward avoiding obstacles.

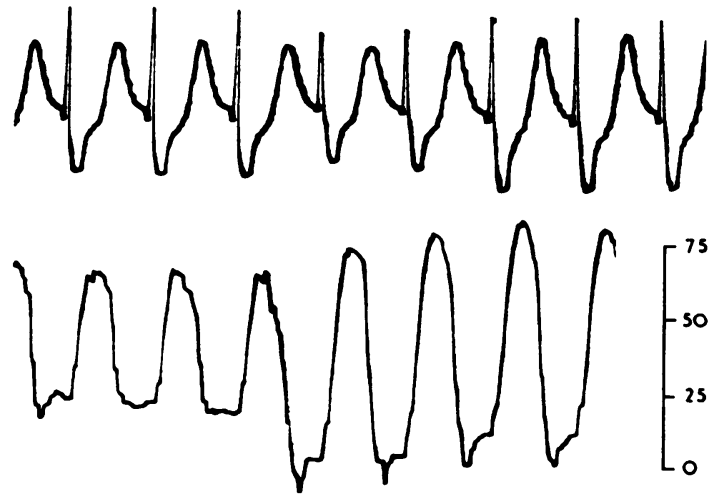

FIG. 8. Case 3. Withdrawal catheter pressure recorded across the pulmonary valve at completion of surgery for a single cusp addition.

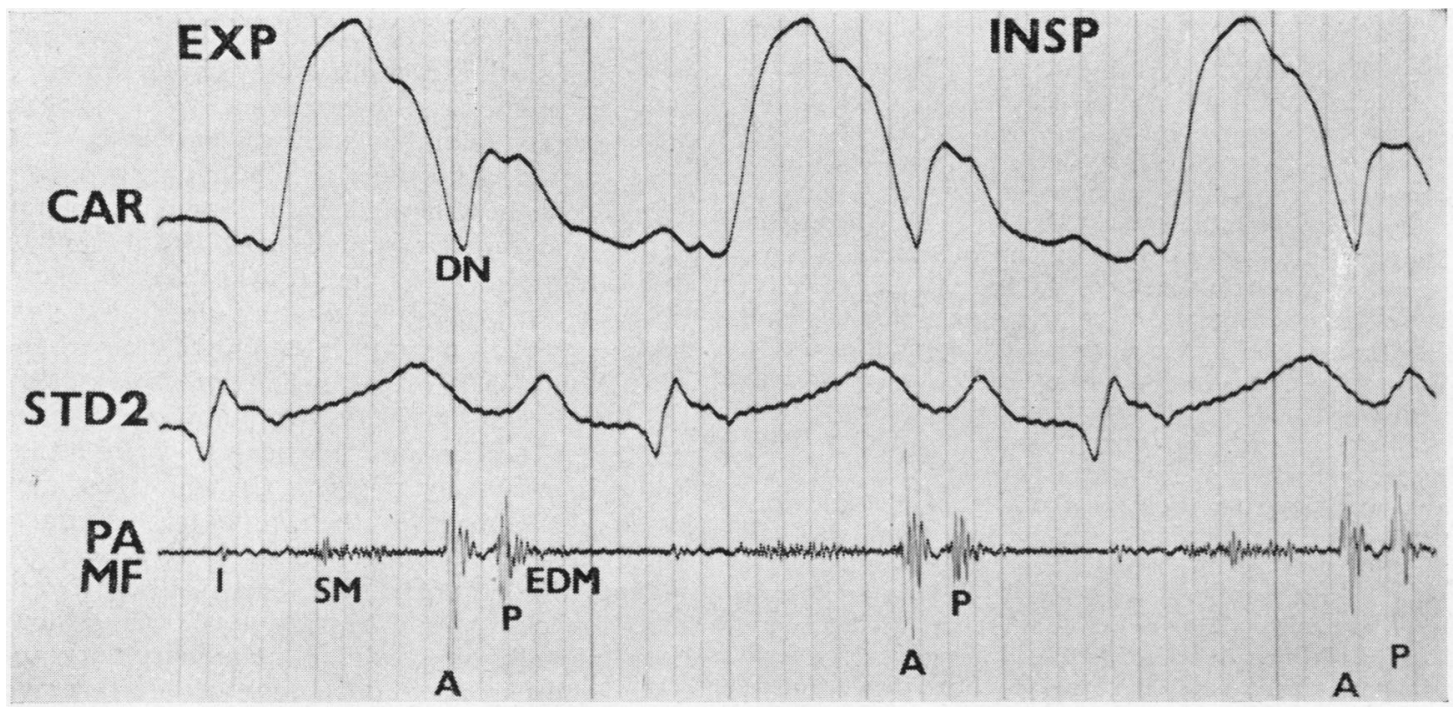

FIG. 7. Case 2. Phonocardiogram six months after tota replacement of the pulmonary cusps. The pulmonary component of the second heart sound is loud. $P_{2}$ follows $A_{2}$ by 0.08 sec. A short early diastolic murmur (pulmonary incompetence) follows $P_{2}$. The abnormally wide and fixed splitting of the second heart sound is due to right bundlebranch block as seen in the reference tracing. A short pulmonary ejection systolic murmur is present (SM). CAR, carotid pulse tracing; STD2, lead II E.C.G.; DN, dicrotic notch; EXP, expiration; INSP, inspiration; PA, pulmonary area; $M F$, medium frequency. 
No retinal changes were seen. He appeared to have peripheral vision only. The cause for this is obscure. He was discharged a month after surgery. Four months later his vision had improved. A soft short ejection systolic murmur and a short early diastolic murmur were present. The second heart sound was widely split and the pulmonary component was soft but audible (Fig. 9). Chest films show a dilated pulmonary trunk and well vascularized lung fields (Figs 10 and 11).

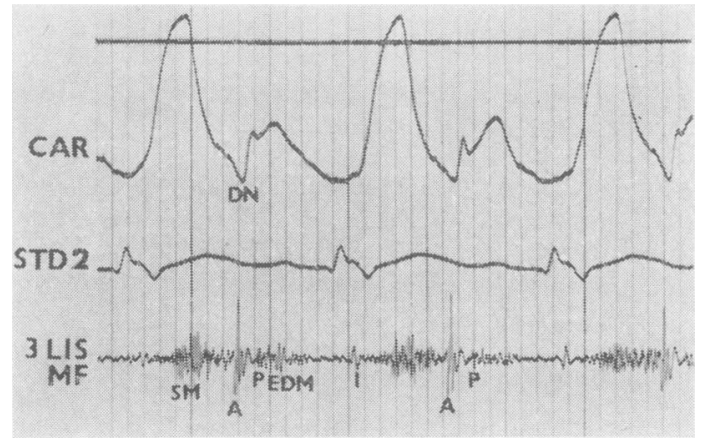

FIG. 9. Case 3. Phonocardiogram taken five months after single cusp replacement. $A$, aortic valve closure; $P$, pulmonary valve closure; $3 \mathrm{LIS}$, third left interspace. A short early diastolic murmur of pulmonary incompetence is present $(E D M)$. The ejection systolic murmur $(S M)$ is moderately loud.

CASE 4 M. E., a girl aged 18, had been cyanosed from birth. In 1954, at the age of 6, a Brock's pulmonary valvotomy was performed by Mr. L. Fatti. The result was excellent and she was only seen occasionally until December 1962, when she complained of breathlessness, dizziness, and headache. She was admitted to hospital and a cerebral abscess was diagnosed and treated by Mr. K. Lewer-Allen. She recovered completely and was next seen in April 1966, when she was cyanosed and dyspnoeic. Dr. J. Barlow confirmed the diagnosis of Fallot's tetralogy with combined infundibular and valvular stenosis.

Operation was performed on 1 November 1966. Dense adhesions were present between the left lung and the right ventricle at the site of the previous ventriculotomy. The pulmonary artery trunk was half the diameter of the aorta. The valve was tricuspid and the commissures fused. Only the posterior cusp was retained. The ring circumference was $4.2 \mathrm{~cm}$. The incision was carried across the ring into the right ventricle for about $2 \mathrm{~cm}$. to just short of the infundibular stricture. This and the bands of infundibular muscle were excised. The ventricular septal defect was patched. The right coronary cusp was then removed from an adult homograft of $7.2 \mathrm{~cm}$. circumference. The non-coronary cusp was sutured below and to the left of the remaining natural posterior cusp and the left coronary above and to the right of it. The recon- structed ring circumference was $6.5 \mathrm{~cm}$. The outflow tract was widened with the mitral leaflet and the pulmonary trunk with aorta. Bypass lasted $100 \stackrel{\vec{\sigma}}{\circ}$ minutes. A pressure gradient of $25 \mathrm{~mm}$. of mercury remained (Fig. 12). The pericardium was left wide open. Post-operatively a considerable left haemothorax developed, but otherwise recovery was? satisfactory.

On discharge a month after surgery a short ejec- $\vec{\omega}$ tion systolic murmur was heard. No early diastolic murmur was present and the pulmonary component $\vec{x}$ of the second heart sound was loud and clear N (Fig. 13).

\section{DISCUSSION}

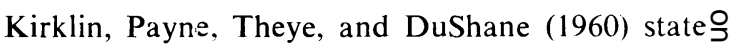
that it is unlikely that a patient will survive opera- tion for Fallot's tetralogy if a residual right $Z$ ventricular pressure greater than $50 \%$ of the aortic pressure remains. This can occur despite the 3 insertion of an adequate outflow patch if the $\mathbb{D}$ pulmonary ring is hypoplastic. Edwards, Carey, $\vec{C}$ Neufeld, and Lester (1965) maintain that the pul- $\mathscr{G}$ monary incompetence which results from division.of the valve ring is seldom severe, because hypertrophy of the right ventricle offers considerable resistance to the retrograde escape of blood from the pulmonary trunk. However, they do not advocate routine division of the ring, because they believe that, after relief of the infundibular and $\vec{F}$ cusp obstruction, the right ventricular muscle 3 becomes thinner and severe incompetence may evolve as a late complication. The question of whether pulmonary incompetence is a progressively serious lesion has been widely debated. With음 good myocardial function, pulmonary incom- ्ָर petence can be tolerated for a long time without serious consequence, and Ellison, Brown, Hague and Hamilton (1955) and Fowler and Duchesne $\delta$ (1958) have proved in healthy dogs that total pulmonary valvectomy is tolerated remarkably응 well. Blount, McCord, Mueller, and Swan (1954) and Price (1961) maintain that pulmonary incom-을 petence is not serious provided the obstructive factor is effectively relieved. On the other hand, $\Omega$ Brock (1959) believes that pulmonary incompe- N tence may present as great a threat as other valve N incompetences, and Bender, Austen, Ebert, Greenfield, Tsunekawa, and Morrow (1963) have shown experimentally that sudden pulmonary incompe- $\frac{C}{\mathbb{D}}$ tence results in acute depression of effective right ventricular function. The very existence of the $\square$ pulmonary valve makes it inconceivable that $\bar{O}$ incompetence is unimportant. It must have a deleterious effect, particularly if myocardial function is impaired through long-standing $\frac{2}{\sigma}$ disease, the ventriculotomy, or bypass. 
Use of a cusp-bearing homograft patch in Fallot's tetralogy

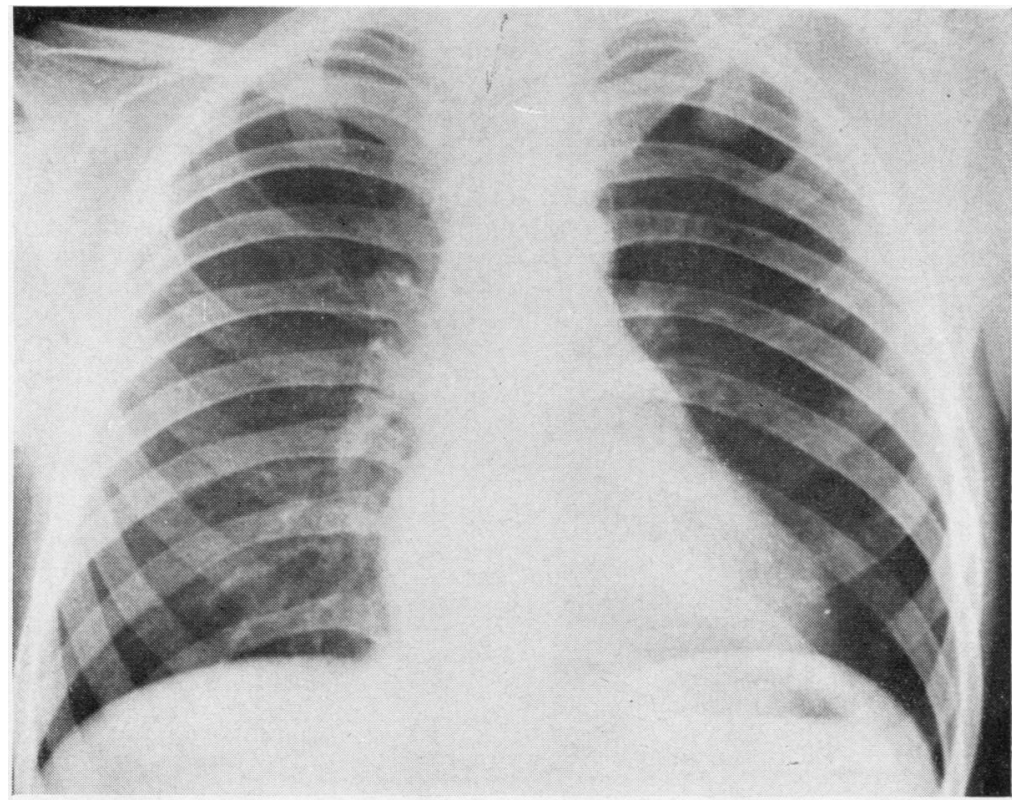

FIG. 10. Case 3. Pre-operative postero-anterior cardiac radiograph immediately before surgery.

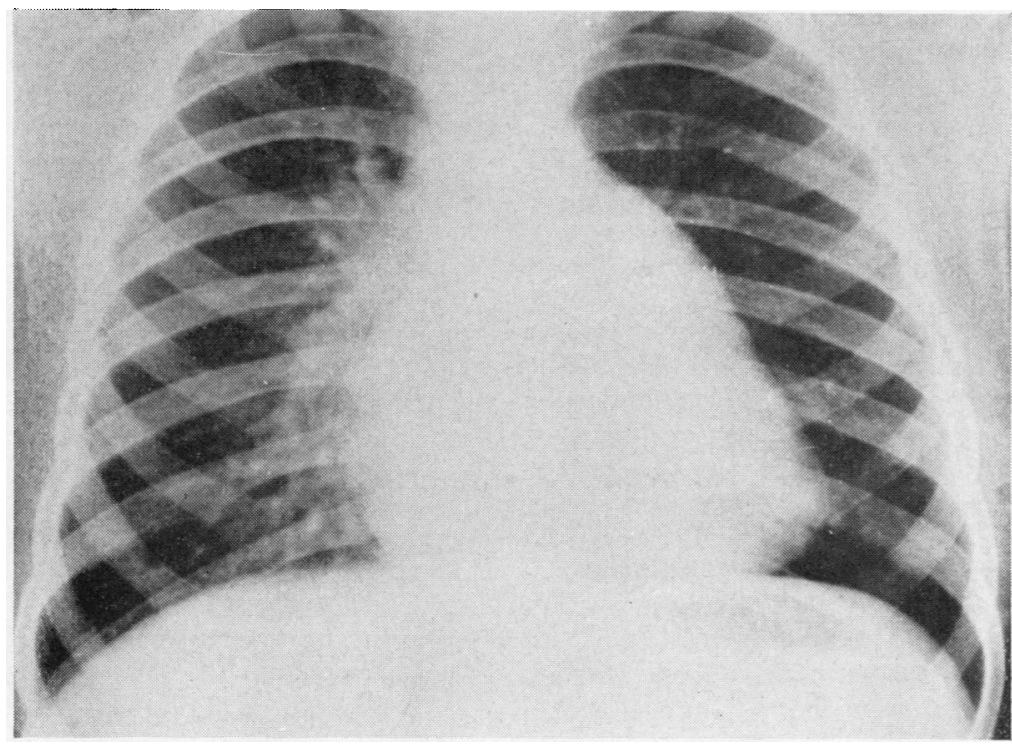

FIG. 11. Case 3. Post-operative postero-anterior cardiac radiograph two months after surgery. Note the enlargement of the pulmonary conus and the improved vascularity of the lungs. 


\section{WAMAMAMWNA}

FIG. 12. Case 4. Needle pressures

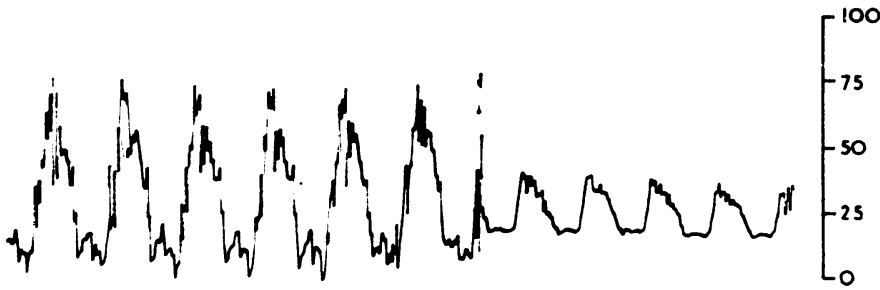
recorded in the body of the righto ventricle and pulmonary trunk aftersurgery for two-cusp replacement. The pulmonary artery pressure $\vec{F}$ appears to be damped.

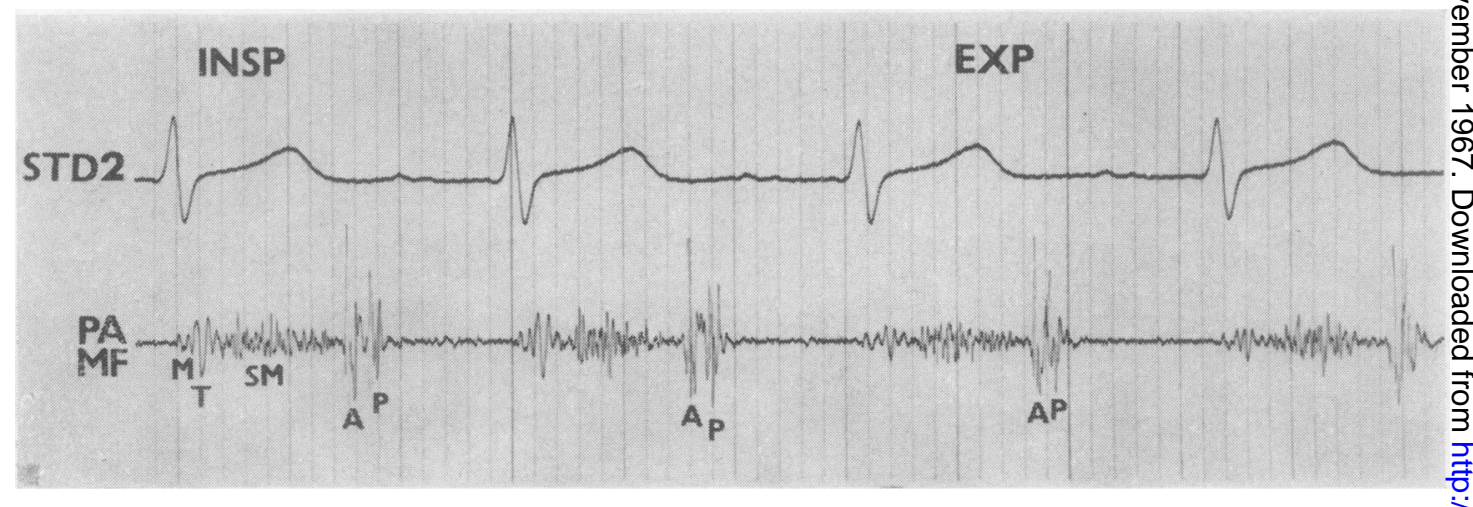

FIG. 13. Case 4. Phonocardiogram three months after operation. The pulmonary component of the second heart sound $(P)$ is loud. Wide splitting of the second heart sound is present. A pulmonary ejection systolie murmur is present. $P A$, pulmonary area; $M$, mitral component of the first heart sound; $T$, tricuspid com $\mathscr{X}^{\cup}$ ponent of the first heart sound.

The valve ring is always small in pulmonary valve stenosis, whereas with isolated infundibular stenosis with a ventricular septal defect the valve ring is normal or near normal in size. The circumferences of the aortic and pulmonary valve rings have been measured in some specimens of our collection of pathological hearts, and the results are given in Table II. Though the tissues were rigid because of preservation, the ratio between the circumference of the aorta and the pulmonary ring is of interest. Expressed in percentages the average ratio between the aorta and pulmonary artery in normal hearts (Table I) is 82 , whereas that in mitral valve disease is 71 , in aortic incompetence 100, in Fallot's tetralogy 160, and in isolated pulmonary valve stenosis 150 . Flow and pressure are important factors in the causation of dilatation or contraction of the valve rings,
T A B L E I I

AVERAGE CIRCUMFERENCE OF AORTA AND PULMON ARY ARTERY IN A VARIETY OF PRESERVED MUSEUM SPECIMENS OF PATHOLOGICAL HEARTS

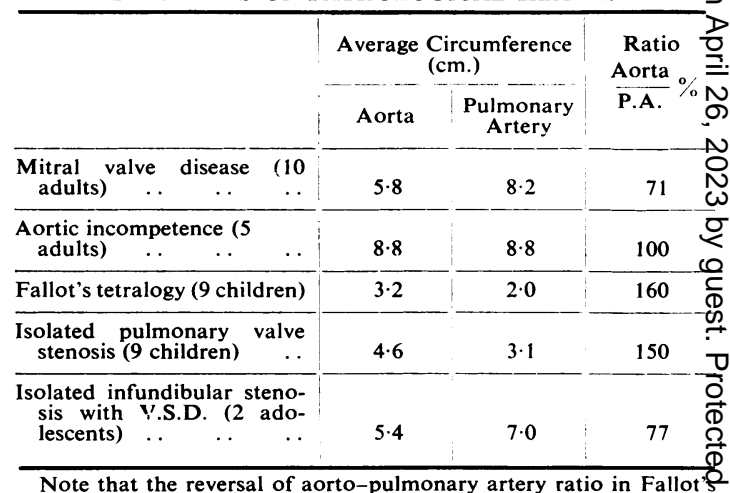

Note that the reversal of aorto-pulmonary artery ratio in Fallot $s$ tetralogy and pulmonary valve stenosis is not found in infundibulap stenosis. 
but, whatever the cause, serious hypoplasia of the valve ring exists in all cases with pulmonary valve stenosis. Not infrequently, a narrowing in the immediate subvalvular position is present. Edwards et al. (1965) have demonstrated that, even after complete resection of the infundibulum, residual obstruction may remain immediately below the cusps. Furthermore, the pulmonary artery trunk is seldom of normal calibre in Fallot's tetralogy. Sabiston, Cornell, Criley, Neill, Ross, and Bahnson (1964) examined the pulmonary arteries of 95 specimens of Fallot's tetralogy and found pulmonary atresia in 22 , severe hypoplasia in 19, and absence in one. The pulmonary arteries were of normal calibre in only two cases. It therefore appears desirable in many cases not only to widen the outflow tract but also to divide the ring and often to enlarge the main pulmonary trunk. Similarly, in pulmonary stenosis with intact septum the valve ring is invariably hypoplastic, though, as Brock (1957) points out, the lumen of the pulmonary artery above the valve is always dilated.

Ideally, every case of pulmonary valvular stenosis should have the ring enlarged to a circumference of from 7 to $9 \mathrm{~cm}$., provided pulmonary incompetence is not induced. It is not always possible to accomplish this even with a cusp-bearing homograft patch. In our first patient the hypoplastic cusps were excised and replaced with a homograft of an 8-year-old child. The final ring circumference was $5.2 \mathrm{~cm}$., and, had this child survived, relative stenosis might have recurred later in life through failure of growth of the homograft. Adult homografts were used for the other cases and the cusp commissures reached almost to the pulmonary artery bifurcation. Because it seemed possible that a circumferential graft, though confined to the valve-bearing area, might impede growth of the natural pulmonary artery and also because of difficulty in obtaining tissue from children, it was decided in the last two patients to preserve posterior continuity of the pulmonary trunk and to use anterior patches carrying either one or two cusps. As it happened, the third case had a bicuspid valve, and a single adult cusp was easily inserted. The final circumference of the orifice was $6.2 \mathrm{~cm}$., which will probably be adequate for this patient throughout life even if the natural pulmonary artery fails to grow. In Fallot's tetralogy it may often be possible to introduce a patch carrying only one cusp, for, as Edwards et al. (1965) point out, the valve in this condition is frequently bicuspid. It remains to be seen whether the discrepancy between the small host cusps and the large adult homograft cusps will result in increasing pulmonary incompetence. At present the three survivors have little or no incompetence, and the important fact is that no serious incompetence was present during the critical early post-operative phase.

When planning the first of these operations consideration was given to excising the pulmonary valves and artery and performing an end-to-end anastomosis between a cylindrical homograft and the transected pulmonary trunk. The homograft ring would have been fixed with posterior stitches and the outflow tract widened with the mitral leaflet. The plan was rejected because it was thought that the risks of haemorrhage would be serious and control of a possible posterior leak would be difficult. Furthermore, the procedure would depend on accurate matching of the host and homograft, and a considerable number of grafts from which to select would be required. In most cases this would exclude the use of an adult vessel. These serious limiting factors were felt to outweigh the advantage of certain competency. As it proved, competence of high degree has been attained by all three methods used.

A further distinct advantage of the technique is that only a small ventriculotomy is required because the ring division enhances the exposure of the infundibular stricture and septal defect. Gerbode and Kerth (1963) have cautioned against large ventriculotomies in Fallot's tetralogy and have advocated the use of a transverse incision so as to limit the number of muscle bundles divided. The short ventriculotomy also lessens the risk of cutting anomalous coronary arteries which so frequently cross the outflow tract towards the anterior interventricular sulcus.

One of the present imponderables is the longterm fate of homografts in this situation. The case we have described (Fuller et al., 1966) has a wellfunctioning valve more than a year after surgery. Already considerable information is available on the fate of homografts in the aortic position up to five years after surgery (Barratt-Boyes, 1964, 1965 ; Barratt-Boyes, Lowe, Cole, and Kelly, 1965: Ross, 1966) and the results are beginning to vindicate the enterprise of Murray (1956). Conditions are not necessarily the same in the pulmonary position, but the possible adverse effect of a venous environment may be balanced by the low diastolic pressures which the homograft has to withstand.

I have to thank Mr. D. Fuller, of our department, for stimulating my interest in the use of homografts in the pulmonary position, and Mr. L. du Plessis for 
his assistance. Drs. J. Barlow and I. Obel have shouldered the burden of pre-operative assessment and post-operative management, and I am deeply indebted to them for their skill and co-operation. The work of the Cardiovascular Research Unit is subsidized by the C.S.I.R. (S.A.), the Johannesburg City Council, and the Wellcome Foundation.

\section{REFERENCES}

Barnard, C. N., and Schrire, V. (1961). The surgical treatment of the tetralogy of Fallot. Thorax, 16, 346.

Barratt-Boyes, B. G. (1964). Homograft aortic valve replacement in aortic incompetence and stenosis. Ibid., 19, 131.

- (1965). A method for preparing and inserting a homograft aortic valve. Brit. J. Surg., 52, 847.

- Lowe, J. B., Cole, D. S., and Kelly, D. T. (1965). Homograft valve replacement for aortic valve. Thorax, 20, 495.

Bender, H. W., Austen, W. G., Ebert, P. A., Greenfield, L. J. Tsunekawa, T., and Morrow, A. G. (1963). Experimental pulmonic regurgitation. J. thorac. cardiovasc. Surg., 45, 451.

Blount, S. G., McCord, M. C., Mueller, H., and Swan, H. (1954) Isolated valvular pulmonic stenosis-clinical and physiologic responses to open valvuloplasty. Circulation, 10, 161.

Brock, R. (1957). The Anatomy of Congenitai Pulmonary Stenosis. Cassell, London.

- (1959). The surgical treatment of Fallot's tetralogy. Guy's Hosp. Rep., 108, 314.

du Plessis, L. A., and Marchand. P. (1964). The anatomy of the mitral valve and its associated structures. Thorax, 19, 221.

Edwards, J. E., Carey, L. S., Neufeld, H. N., and Lester, R. G. (1965) Congenital Heart Disease, Vol. 2. W. B. Saunders, Philadelphia and London.

Ellison, R. G., Brown, W. J., Hague, E. E., and Hamilton, W. F. (1955). Physiologic observations in experimental pulmonary insufficiency. J. thorac. Surg., 30, 633.

Fowler, N. O., and Duchesne, E. R. (1958). Effect of experimental pulmonary valvular insufficiency on the circulation. Ibid., 35, 643.

Fuller, D. N., Marchand, P., Zion, M. M., and Zwi, S. (1966). Homograft replacement of the pulmonary valve. Thorax, 21, 337 .

Gerbode, F., and Kerth, W. J. (1963). Technical considerations in the treatment of tetralogy of Fallot-the transverse ventriculotomy. Ann. Surg., 158, 975.

Kirklın, J. W., Payne, W. S., Theye, R. A., and DuShane. J. W. (1960). Factors affecting survival after open operation for tetralogy of Fallot. Ibid., 152, 485.

- Donald, D. E., Harshbarger, H. G., Hetzel, P. S., Patrick, R. T. Swan, H. J. C., and Wood, E. H. (1956). Studies in extracorporeal circulation. Applicability of Gibbon-type pumpoxygenator to human intracardiac surgery: 40 cases. Ibid., $144,2$.

Lillehei, C. W., Cohen, M., Warden, H. E., and Varco, R. L. (1956). Complete anatomical correction of the tetralogy of Fallot defects. Report of successful case. Arch. Surg., 73, 526.

- Morris, M. J., Adams, P., and Anderson, R. C. (1964). Corrective surgery for tetralogy of Fallot. $J$. thorac. cardiovasc. Surg., 48, 556.

Marchand, P. (1958). The management of a blood vessel bank. S. Afr. med. J., 32, 423 .

Murray, G. (1956). Homologous aortic-valve-segment transplants as surgical treatment for aortic and mitral insufficiency. Angiology. $7,466$.

Price, B. O. (1961). Isolated incompetence of the pulmonic valve. Circulation, 23, 596.

Ross, D. N. (1966). Aortic valve surgery. Ann. roy. Coll. Surg. Engi., $39,192$.

Sabiston, D. C., Cornell, W. P., Criley, J. M., Neill, C. A., Ross, R. S., and Bahnson, H. T. (1964). The diagnosis and surgical correction of total obstruction of the right ventricle. J. thorac. cardiovasc. Surg., 48, 577.

\section{ADDENDUM}

The three surviving patients were seen by Drs. J. Barlow and I. Obel at the Cardiac Clinic of the
Johannesburg General Hospital during July 1967 . 등 Case 2 is well and the early diastolic murmur remains faint. It is now 11 months since his $\frac{\vec{\sigma}}{\sigma}$ operation. Case 3 still has central blindness. although his field of vision is expanding and\% cardiologically he is in excellent condition $10 \vec{\circ}$ months after surgery. The short early diastolicmurmur remains and the degree of pulmonaryc incompetence is moderate. Case 4 underwent cardiac catheterization on 7 July 1967. Nox systolic gradient is present and a satisfactory N diastolic pressure was found in the pulmonaryos artery. Right-sided angiograms were performed. $\overrightarrow{0}$ The pulmonary artery trunk is of wide calibre (Fig. 14). Dye was injected into the main pul-o monary trunk (Figs 15 and 16) and this shows the presence of a mild degree of pulmonaryo incompetence. The homograft cusps were quite clearly outlined (Fig. 16) and on ciné-angiographyב्믐 they appeared to be mobile. The sinuses of Valsalva are deep. A short faint early diastolic $\vec{\oplus}$ murmur can be heard. It is now eight monthso since her operation.

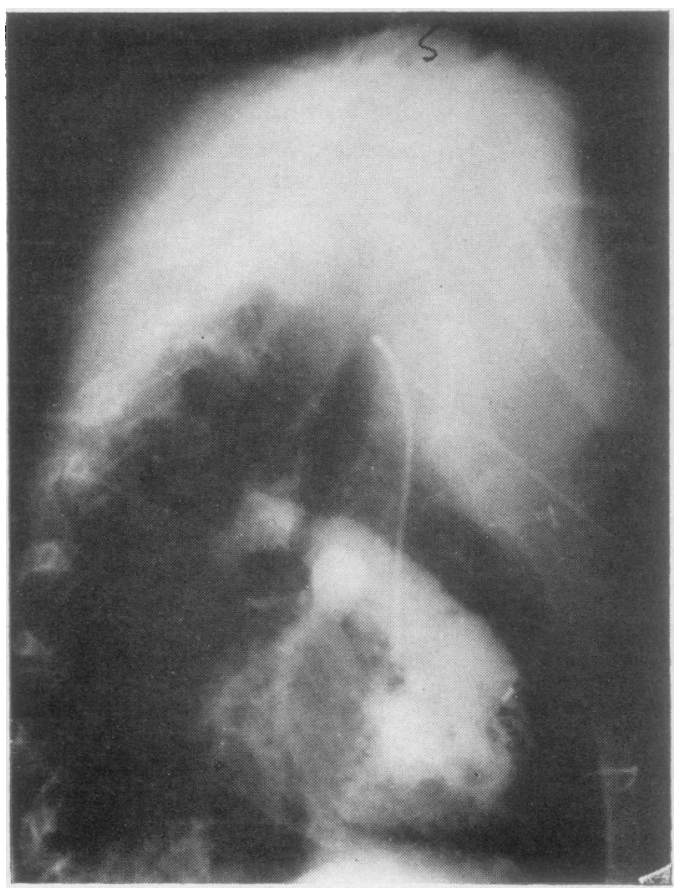

FIG. 14. Radiograph taken in the lateral position with dye injected into the right ventricle. The wide calibre of the pulmonary trurk is seen. 


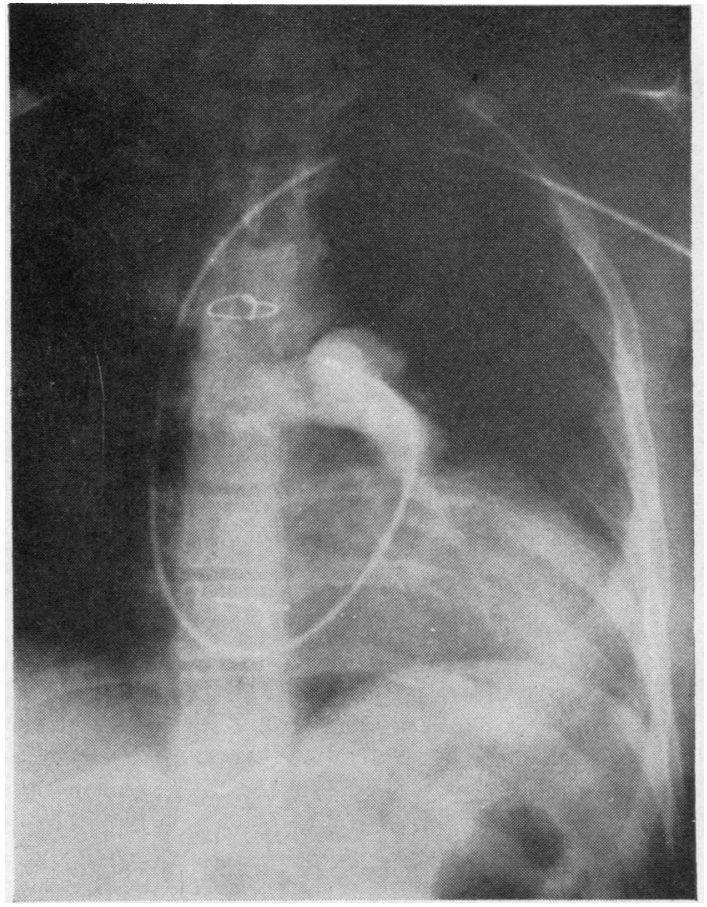

FIG. 15

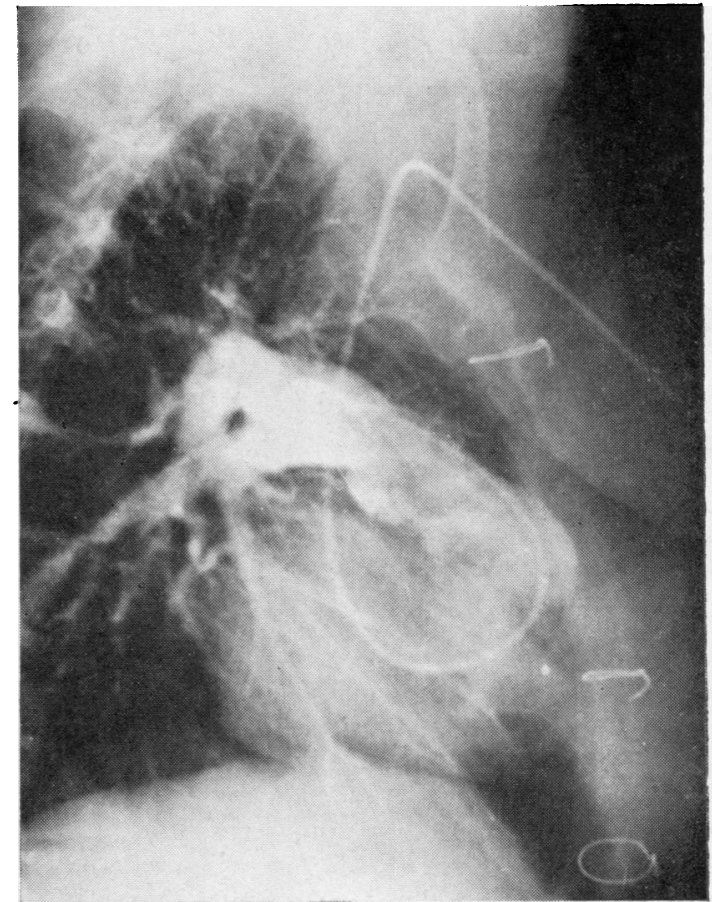

FIG. 16

FIG. 15. Angiocardiogram performed in the A.P. position with injection of Urografin into the main pulmonary artery. Regurgitation is minimal. The homograft cusps are outlined.

FIG. 16. Angiogram performed in the right anterior oblique position whilst dye was injected into the main pulmonary artery. In this caso the posterior cusp of the host was retained and two anterior homograft cusps were introduced. Regurgitation is minimal and might be due in part to distortion by the catheter, which lies anteriorly. 